\title{
Ethnic Minority Concentration: A Source of Productivity Growth for Italian Provinces? ${ }^{\S}$
}

\author{
Alessandra Michelangeli $^{*} \quad$ Nicola Pontarollo $^{\$}$ Giuseppe Vittucci-Marzetti ${ }^{\times}$
}

August, 2017

\begin{abstract}
This paper aims at assessing the contribution of ethnic minorities to the (total and sectoral) productivity of Italian provinces. We consider the first ten nationalities by numbers of legal immigrants at the provincial level (NUTS-3) 2003-2011. We estimate a spatial panel model to capture both direct and indirect effects of foreign communities on local productivity at the province level, accounting for spatial spillovers. Our findings show that two communities out of the ten considered have a direct positive impact on aggregate labour productivity. Other foreign groups have significant indirect effects: these groups do not affect productivity of provinces where they live, but mainly of the neighbouring provinces, likely because of commuting.
\end{abstract}

Keywords: Productivity growth; Specialisation; Spatial panel models; Foreigners.

JEL Codes: R11; R12; R23.

$\S$ The views expressed are the authors' and do not necessarily correspond to those of the European Commission. Financial support by the Italian Ministry of University and Research is gratefully acknowledged. We would like to thank participants at ERSA Summer School 2016 (Polytechnic of Milan), and at the18th annual Meeting of the Association for Public Economic Theory (University Pantheon-Assas, Paris).We would like to thank also the three anonymous reviewers for their insightful and detailed reports. The usual disclaimer applies.

* Corresponding author: Department of Economics, Management and Statistics, University of Milan-Bicocca, Piazza dell'Ateneo Nuovo 1, 20126 Milan (Italy), email: alessandra.michelangeli@unimib.it

\$ Joint Research Centre European Commission, Via Enrico Fermi 2749, I, 21027 Ispra (Italy), email: nicola.pontarollo@ec.europa.eu

$\times$ Department of Sociology and Social Research, University of Milan-Bicocca, Piazza dell'Ateneo Nuovo 1, 20126 Milan (Italy), email: giuseppe.vittucci@unimib.it 


\section{Introduction}

In the last fifteen years, Italy has seen a significant increase in immigrant population, rising from just over one million (3.04\% of total population) in 2001 to 4.9 million $(8.1 \%)$ at the beginning of 2014. The foreign-born population resident in Italy has increased at a rate lower only than the rate of Spain (OECD, 2016). Historically, migrants in Italy have all tended to settle mainly in the North and the Centre. Their characteristics, as well as their distribution across productive sectors, have been quite heterogeneous. According to INEA (2009), 3.9\% of foreign residents are employed in the agricultural sector, $40.9 \%$ in the industrial sector, and $55 \%$ in services. While a growing literature analyses the impact of total migrant inflows on the economic growth of the host country, almost none distinguishes ethnic minorities on the basis of their spatial distribution. Among the more recent contributions, Kangasniemi et al. (2012) and Nicodemo (2013) find a negative impact on productivity level for Spain, a country that, like Italy, experienced a productivity reduction in the last years. On the contrary, Rolfe et al. (2013) find a positive effect of migrants (not distinguished by ethnicity) on the whole productivity growth for the United Kingdom that seems able to attract skilled people from abroad. Other studies, such as Alesina et al. (2003), Easterly and Levine (1997), Montalvo and Reynal-Querol (2005) and Gören (2014), focus on the effect of ethnic fragmentation on economic growth. Barro and McCleary (2003), Noland (2005) and Sala-i-Martin et al. (2004), finally, investigate the relationship between different religions and economic performance. ${ }^{1}$ In this paper, we shift the analysis on foreign groups of different nationalities, which are clustered in space and tend to be specialised in certain occupations. The aim is to investigate

\footnotetext{
${ }^{1}$ Researchers have also investigated the impact of immigration and ethnic diversity/concentration on housing prices (e.g. Accetturo et al., 2014; Li, 2014; Mussa et al., 2017), innovation (e.g. Ozgen et al., 2013) and natives' well-being (Akay at el., 2014).
} 
whether and to what extent ethnic minorities contribute to Italian productivity in five key sectors: agriculture, industry, construction, high services (office and professional work), and low-services (wholesale, retail, hotels and catering, transport and distribution, housework).

We consider the first ten nationalities by numbers of legal immigrants, according to the latest 2011 census data, which account for $63.79 \%$ of the total foreign population resident in Italy. ${ }^{2}$ They are observed at the provincial level (NUTS-3) from 2003 to 2011. We use a spatial panel model, which captures both direct and indirect effects of each community on productivity, accounting for possible spatial spillovers. To the best of our knowledge, the specific contribution to local productivity of foreign groups and the effect of their spatial distribution have not yet been empirically investigated. This paper is a first attempt to provide some meaningful results for the Italian case.

The rest of the paper is organised as follows. Section 2 presents an overview of recent trends in foreign migration across Italian provinces. Section 3 introduces the model. Section 4 shows the results. Section 5 concludes.

\section{Ethnic minorities in Italy}

Italy has experienced mass immigration since $2000 .{ }^{3}$ The largest ethnic group was from Morocco in 2001, followed by Albania and Romania. These countries continue to be the most represented, with only a slight change in the ranking: Romania became first since 2007, Albania second and Morocco third. The other most represented groups are from Asia (in particular, China and Philippines), North-Africa (Tunisia and Morocco), East-Europe (Albania, Romania,

\footnotetext{
${ }^{2}$ Foreigners from other countries are less than 100,000 per country.

${ }^{3}$ Italy has seen significant inflows of immigrants from Albania since 1991, after the collapse of the Communist bloc. In 1990, a first law was approved trying to regulate the entry flows, as well as to introduce an immigration amnesty for about 200,000 foreigners, mainly from North Africa, who were already in Italy. However, the number of foreign residents is less than one million until 1997 over a total population of 56 million inhabitants, less than $1.7 \%$.
} 
Moldova, Poland, Ukraine). According to official statistics and statistical surveys by Leone Moressa Foundation (2012), foreign people usually work in low-skilled jobs concentrated in three sectors: agriculture, construction and low-services. Table 1 reports the specialisation of the first 10 nationalities, determined by the largest employment share of each community across sectors.

Table 1: Ethnic community specialisation

\begin{tabular}{llc}
\hline \hline Country & Specialisation & Occupied (\%) \\
\hline Albania & Construction & 27.5 \\
Romania & Low-services (in particular housing and personal services) & 25.2 \\
China & Commercial sector & 48.7 \\
Philippines & Low-services (in particular housing and personal services) & 77.4 \\
Morocco & Construction & 14.1 \\
Moldova & Low-services (in particular housing and personal services) & 46 \\
Poland & Low-services (in particular health care, housing and personal services) & 37.2 \\
Tunisia & Construction & 19.5 \\
Ukraine & Low-services (in particular health care, housing and personal services) & 67.2 \\
India & Agriculture & 16.3 \\
\hline \hline
\end{tabular}

Source: Leone Moressa Foundation (2012).

Some ethnic groups are more specialised than others. Among the more specialised ones, there are the groups from Philippines, Ukraine and China. The most fragmented groups are from India, Morocco, Tunisia, Albania and Romania. People from Albania, Morocco and Tunisia are mainly employed in construction; people from Poland, Ukraine, Moldova and Philippines in health care services, child care, personal and housing services; people from China in commerce, specifically in the textile and clothing sector. People from India are mainly employed in agriculture, that employs also a significant percentage of Tunisians (11.7\%).

The distribution of foreign groups is observed in 103 Italian provinces (NUTS-3), at the lowest level of disaggregation for which the data are available, from 2003 to $2011 .^{4}$ Data on foreign

\footnotetext{
${ }^{4}$ In mid-2005, four new provinces were created in Sardinia: Carbonia-Iglesias, Medio Campidano; Ogliastra, Olbia-Tempio. As for these provinces there are missing data and bilateral migration flows are quite small, we reassigned each of these new provinces to the province in which it was originally incorporated: Carbonia-Iglesias and Medio Campidano to Cagliari; Ogliastra to Nuoro; Olbia-Tempio to Sassari.
} 
residents by nationality come from the Italian National Statistical Institute (ISTAT) and cover regularly registered foreigners. Data on sectoral employment and Gross Value Added (GVA) in real terms (base year 2005) at the province level are from the Cambridge Econometrics Database.

Table 2 reports the correlation between the initial regional GVA per employee (year 2003) for each of the six sectors and the proportion of minority groups over the total population in each region. The correlation is generally low and positive, meaning that there is a weak tendency for immigrants to settle in provinces where the sectoral GVA per employee is higher. There are few cases showing a correlation above 0.20 . The sector with the highest correlation is agriculture for people coming from Albania and construction for Albania and Marroquins, with 0.24 and 0.30 , respectively. We observe a negative correlation between initial GVA per employee in low-level services for all the nationalities, with the exception of India. Initial GVA per employee in high-level services shows a negative correlation in half the cases, while the GVA per employee in the construction sector has a negative correlation in three cases.

Table 2. Correlation between GVA per employee and share of immigrants by nationality

\begin{tabular}{lcccccc}
\hline \hline & Total & Agriculture & Industry & Construction & $\begin{array}{c}\text { High lev. } \\
\text { services }\end{array}$ & $\begin{array}{c}\text { Low lev. } \\
\text { services }\end{array}$ \\
\hline Albania & 0.3007 & 0.4679 & 0.1769 & 0.2402 & 0.1067 & -0.1269 \\
Romania & 0.1597 & 0.2459 & 0.1028 & -0.0356 & -0.1243 & -0.1208 \\
China & 0.1347 & 0.2249 & 0.1202 & 0.0756 & -0.0149 & 0.0185 \\
Philippines & 0.2322 & 0.2731 & 0.1809 & 0.0718 & -0.0658 & -0.1623 \\
Morocco & 0.3416 & 0.3118 & 0.2662 & 0.2925 & 0.0867 & -0.0147 \\
Moldova & 0.1616 & 0.2262 & 0.1376 & 0.1355 & 0.0157 & -0.0802 \\
Poland & -0.1137 & 0.0479 & -0.2186 & -0.3579 & -0.1900 & -0.1786 \\
Tunisia & 0.1311 & 0.1944 & 0.0648 & 0.0776 & 0.1032 & -0.0643 \\
Ukraine & 0.1345 & 0.2356 & 0.0564 & -0.0257 & -0.2406 & -0.1565 \\
India & 0.1981 & 0.2405 & 0.1486 & 0.1779 & 0.0357 & 0.0838 \\
\hline \hline
\end{tabular}

Figure 1 reports, on the left axis, the variance of the share of foreigners over total population 
and, on the right axis, their spatial clustering at the province level measured by Moran's I. ${ }^{5}$

Figure 1. Variance and Moran's I of foreign-born population over population

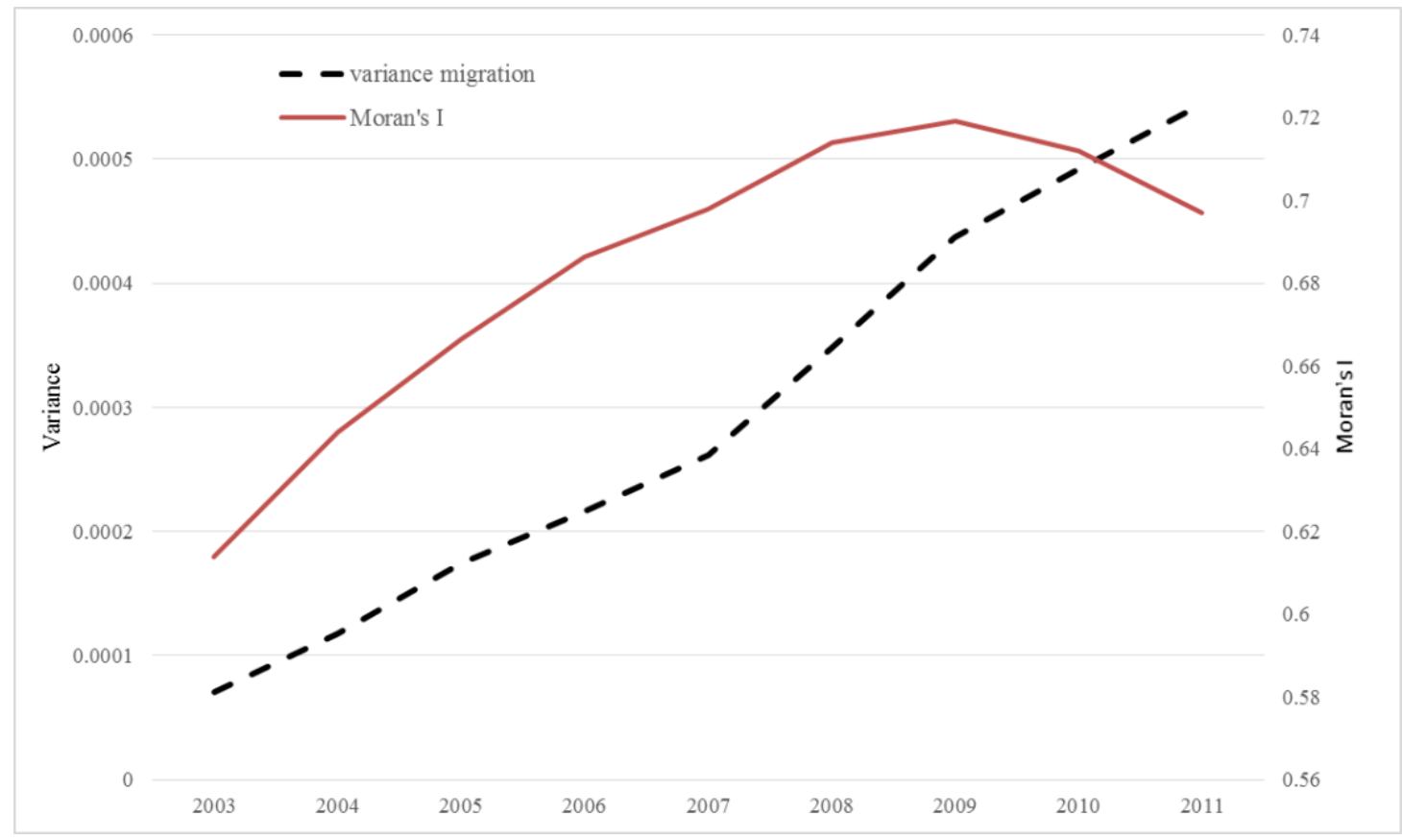

The insights from this graph are threefold. First, there is strong evidence of positive spatial autocorrelation (the bootstrapped $p$-values are always smaller than 0.01 in all years). Migration tends to cluster: provinces having a relatively high (low) share of foreign population are located near provinces with high (low) percentage of foreign population. ${ }^{6}$ Most spatially concentrated foreign groups are from Albania, Romania, Morocco, Poland and Ukraine, with Moran's I between 0.40 and 0.62. The less concentrated foreign groups are from Philippines, Tunisia, Moldova and India, with a Moran's I between 0.10 and 0.32 . Moran's I is not statistically significant for people from China, which are quite dispersed across provinces. Foreign community clustering, found also by González and Ortega (2011) for Spain, is likely driven by

\footnotetext{
${ }^{5}$ The spatial weights matrix $\mathbf{W}$ used to compute the index is a (row-standardized) binary contiguity matrix. The elements of $\mathbf{W}$ take the value of 1 if the pair of provinces shares a border, and 0 otherwise. In the case of some of the provinces in Sicily and Sardinia, we imputed a value of 1 for the provinces separated by a few kilometers of sea-water. Moran's I varies between -1 and 1 . A positive (negative) coefficient hints at a positive (negative) spatial autocorrelation, i.e. similar (dissimilar) values cluster together in a map.

${ }^{6}$ Moran correlations by ethnic group are reported in the Appendix (Table A1).
} 
at least three factors: $i$ ) the presence of people of the same community already settled down in a given province, or in the neighbouring provinces (this is the so-called chain migration); ii) the economic conditions in terms of job opportunities in the province; iii) the endowments of infrastructures, local goods and services affecting the living conditions of newcomers. The existence of clusters implies that foreign communities in a province cannot be seen as independent from those in the other provinces. This evidence leads us to adopt an empirical strategy that takes into account the spatial dependence of community distribution across provinces.

The second interesting insight is that spatial autocorrelation increases until 2009, then slightly decreases. This could be a consequence of the Great Recession, which affected both the location decisions of people already living in Italy and the choice of foreigners to migrate to this country. The third insight is the co-movement between the percentage of foreign people's variance and Moran's I up to 2009, and then a divergence between the two measures. Until 2009, the spatial dependence strengthens as the foreign dispersion increases, implying that the clusters at the province level are likely to become more similar over time, with a stronger spatial pattern that translates itself into an increasing variance. Since 2009, the spatial dependence slightly decreases while the foreign dispersion continues to increase. The clusters of provinces, which become more similar over time, are clearly observable in Figure 2, in which the percentage of foreign-born population is represented for years 2003 (Figure 2a) and 2011 (Figure 2b). 
Figure 2. Percentage of foreign-born population over total population

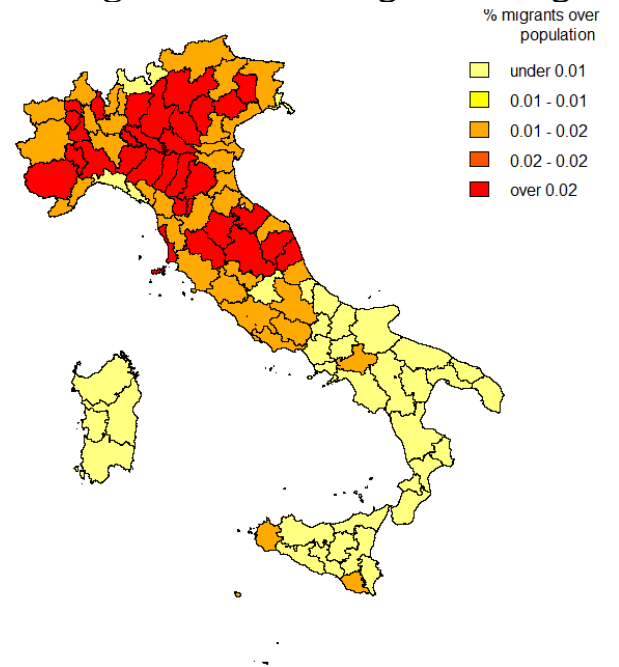

a) 2003

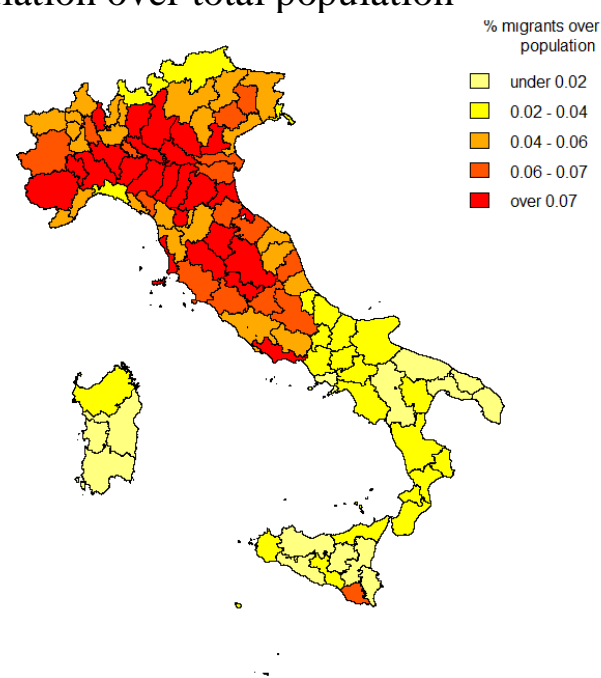

b) 2011

The rising inflows of migrants in Italy tend to concentrate in the North and the Center, increasing the gap with the South.

Since our analysis focuses on the relationship between productivity growth and ethnic minority concentration, we report a brief overview of productivity dynamics over the period 2003-2011. Figure 3 shows the so called $\sigma$-convergence, i.e. the dispersion of the (log) of GVA per employee and Moran's I of the same variable over time. Also in this case there is a strong evidence of spatial dependence of labour productivity, ${ }^{7}$ which we shall take into account in Section 3.

Note that Moran's I is quite volatile between 2003 and 2007, then it tends to decline together with the variance of the (log) GVA per employee. These patterns imply that, at least since 2008, productivity levels have been slightly less spatially dependent and differences in productivity across provinces have decreased. The decreasing spatial dependence might be due to the fact that provinces in each cluster become less similar in their productivity, or that the number of spatial clusters is decreasing over time (Rey and Montouri, 1999). The lower degree of

\footnotetext{
${ }^{7}$ Moran's I is statistically significant in all the periods.
} 
variability across provinces is explained by a decline of productivity particularly in the Northwest provinces, mainly due to a problem of misallocation of resources (Calligaris et al., 2016). The result is a more equal but less productive country.

Figure 3: Variance and Moran's I of $\log (\mathrm{GVA} / \mathrm{emp})$

Figure 3. Variance and Moran's I of $\log (\mathrm{GVA} / \mathrm{emp})$

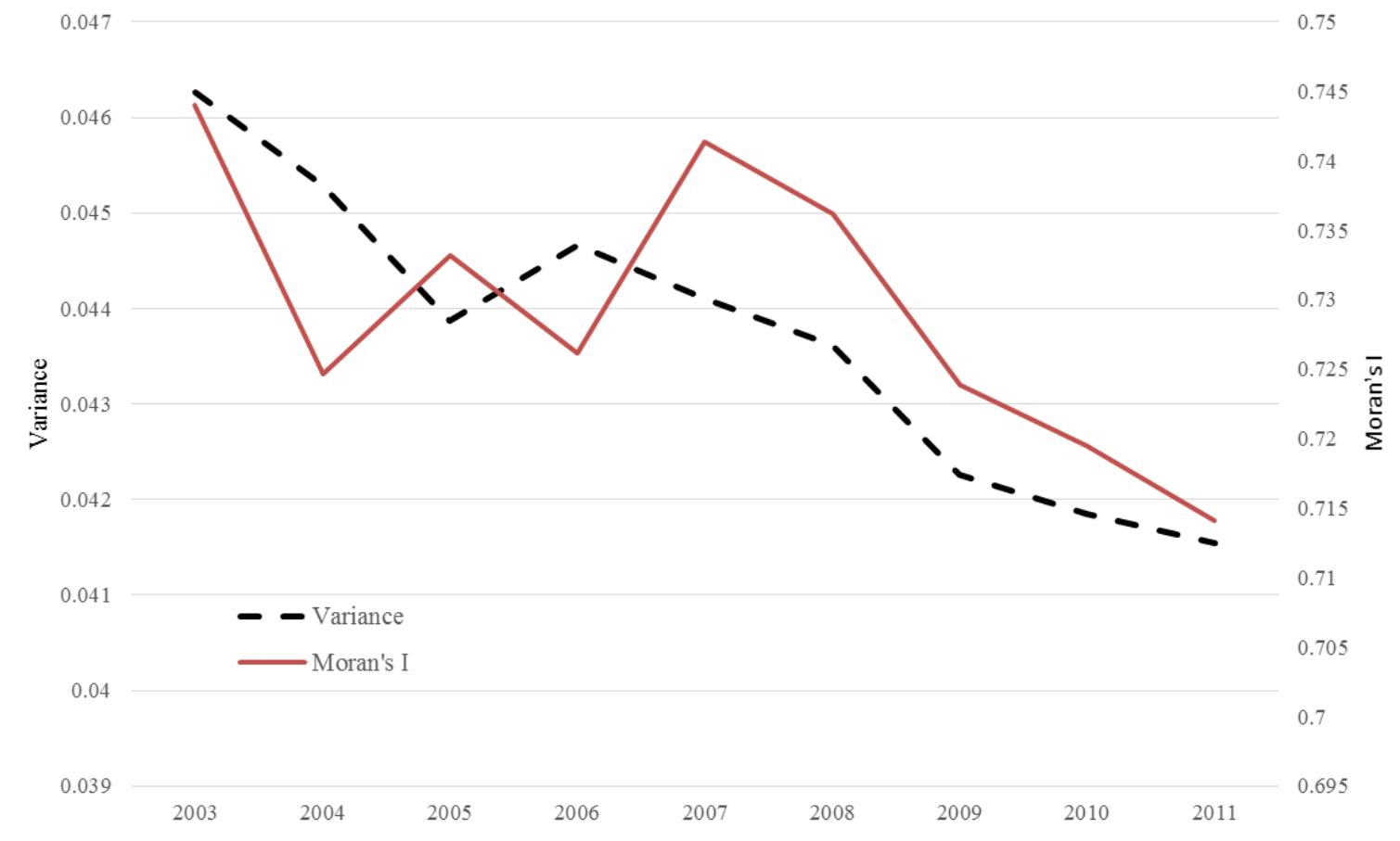

Figure 4 depicts the relation between the annual productivity growth rate and the share of foreign population (at the beginning of each year) for the period 2003-2011. There is a clear negative correlation between the share of foreigners and the productivity growth; no leverage points or influent outliers are statistically detected. 
Figure 4: Scatter plot (with least squares fit) of the percentage of foreign population and the average GVA/emp growth rate 2003-2011 by province.

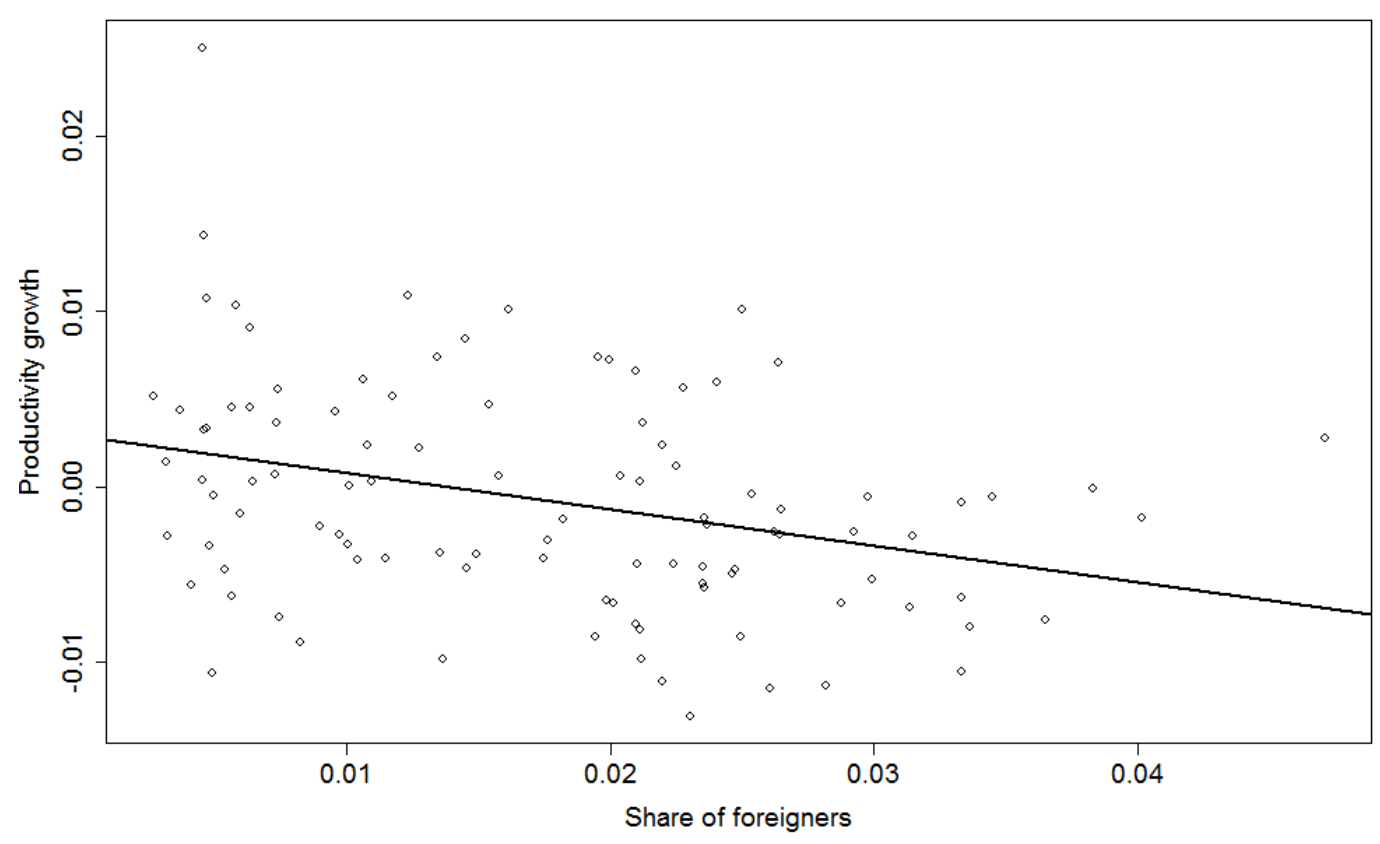

This preliminary analysis shows a spatial concentration of foreigners in the Centre and the North of Italy, which seems not to improve productivity. In what follows, we shall go deeper into the analysis by introducing a theoretical model and the empirical methodology to estimate it.

\section{Theoretical framework and empirical methodology}

Our model assumes that ethnic minorities may affect productivity because of their productive specificities. This assumption reflects the perspective of a recent strand of literature that highlights how migrants' specificities might play a role in the host economy. Immigrant workers have cultural traits (i.e., language, habits, religious beliefs, of the community they belong to), in addition to individual-specific abilities. As a consequence, natives and foreignborn workers, even with the same educational levels, may specialize in different tasks, leading the economic system to a more efficient allocation of skills to tasks (Peri, 2012; Etzo et al., 
2016).

The model can be considered to be somewhat in the spirit of the human capital model of de la Fuente and Doménech (2006), later extended by Ramos et al. (2010). It considers a CobbDouglas production function, expressed as follows:

$Y_{i t}=K_{i t}^{\alpha} H_{i t}^{\beta}\left(A L_{i t}\right)^{1-\alpha-\beta}$

where $Y$ is the output, $K$ the capital, $H$ the skills of foreign workers, $L$ the labour force and $A$ is a technology index. Subscripts $i$ and $t$ denote, respectively, the geographical unit (province) and the time-period.

Taking the logs and dividing all the variables by the effective quantity of labour, $A L_{i, t}$, we obtain:

$y_{i t}=\alpha k_{i t}+\beta h_{i t}$

where $h_{i, t}$ represents ethnic community skills per unit of effective labour. As mentioned in Section 2, we have some insights on ethnic community skills from the prevalent occupation, as reported in Table 1 . This leads us to use the percentage of people of nationality $e$ over the total population as a proxy for ethnic community skills per unit of effective labour. Accordingly, equation (2) becomes:

$y_{i t}=\alpha k_{i t}+\sum_{e=1}^{E} \beta^{e} h_{i t}^{e}$

The coefficient $\beta^{e}$ measures the effect of a marginal increase in the proportion of people of nationality $e$ on the output per effective worker. The expected sign of this coefficient cannot be determined a priori. A positive effect may be explained by: (i) a more efficient allocation of skills to tasks; (ii) the birth or relocation of firms; ${ }^{8}$ (iii) the complementarity relationship between minority group $e$ and native-born workers in a given province. Instead, a negative effect may be due to the fact that immigrant workers have been substitutes for native-born

\footnotetext{
${ }^{8}$ Etzo et al. (2016) investigate the impact of immigration at the Italian provincial level between 2004 and 2010 and show that an increase in the relative size of the foreign workforce has a positive impact on the local economy in terms of the number of establishments and total employees.
} 
workers and have produced lower quantity of output per worker and, in some cases, they have worsened the product quality. ${ }^{9}$ In Section 4 , we shall interpret our empirical results in light of these considerations.

Equation (3) is modified to carry out the empirical analysis on a panel of the 103 Italian provinces in the 2003-2011 period. We start with the following specification:

$y_{i, t}=\mu_{i}+\tau_{t}+\sum_{e=1}^{E} \beta^{e} h_{i, t-2}^{e}+\delta \operatorname{spec}_{i, t-2}+\varphi \operatorname{div}_{i, t-2}+\varepsilon_{i t}$

where $\mu_{i}$ is a spatial fixed effect (which embodies the initial local productivity level, $y_{i, 0}$, and accounts also for conditional convergence effects) ${ }^{10} \tau_{t}$ is a time-period fixed effect; $\operatorname{spec}_{i, t-2}$ is a measure of specialization, given by the employment share of each province largest sector at $t-2$ (the share of each sector in local employment is divided by its share in national employment, as in Duranton and Puga, 2000); $d i v_{i, t-2}$ is the inverse of the HirschmanHerfindahl index, a measure of industrial diversity; finally, $\varepsilon_{i t}$ is the error term.

Selection concern may arise since per capita GDP (correlated with productivity levels) could guide the selection of minority groups into provinces. However, the lack of systematic differences in ethnic minority shares across provinces by sector, shown in Section 2 (see Table 2) decreases the concern that per capita GDP guides the selection of ethnic minority groups. The assumption underlying specification (4) is that (sectoral) GVA per employee in a province is independent of (sectoral) GVA per employee in other provinces. However, as pointed out by

\footnotetext{
${ }^{9}$ Llull (2008) estimates that, in OECD countries, on average an immigrant is equivalent two thirds of the efficiency units of a native. Kangasniemi et al. (2012) show that the negative impact of immigrants on productivity in Spain has been the result of the combined quantity and quality effect.

${ }^{10}$ Given the limited time span of our analysis, this can be considered also a first-order Taylor expansion around the steady-state of a growth equation. We preferred this simple approach over the estimation of a full-fledged growth regression in a panel context as this greatly simplifies the analysis in the spatial extension of the model. In fact, in order to consistently estimate dynamic spatial models with spatial and time-period fixed effects, at present, one has to rely either on: i) the QML estimator put forward by Yu, de Jong and Lee (2008), extended by Lee and Yu (2010) to include time-period fixed effects; or ii) GMM estimators, i.e., the Arellano and Bond (1991) DIFFGMM and Blundell and Bond (1998) SYS-GMM estimator (see Elhorst, 2014, Ch.4). As for the former, Elhorst (2010b) shows that, when T is small, as it happens in our case, this estimator is severely biased. As for the Arellano and Bond DIFF-GMM and Blundell and Bond SYS-GMM estimator, as recently discussed by Lee and Yu (2014), these estimators can be severely biased (they suggest to use quadratic moments conditions to reduce the bias).
} 
Fingleton and López-Bazo (2006), (sectoral) GVA per employee in a certain region is likely to be influenced by the economic performance in the neighbouring regions, because they are interdependent and cannot be treated as "isolated islands" (Mankiw, 1995; Quah, 1996). If such spatial dependence is not taken into account, results are likely to be inconsistent and may lead to misleading conclusions. Given the spatial dependence in economic performance across provinces shown in Figure 3, we adopt an estimation strategy able to account for externalities across provinces.

Equation (4) is augmented with spatially lagged dependent and spatially lagged independent variables, as follows:

$\boldsymbol{y}_{t}=\boldsymbol{\mu}_{i}+\boldsymbol{\tau}_{t}+\rho \mathbf{W} \boldsymbol{y}_{t}+\sum_{e=1}^{E} \beta^{e} \boldsymbol{h}_{t-2}^{e}+\delta \boldsymbol{s p e c}_{t-2}+\varphi \boldsymbol{d i v}_{t-2}+$

$+\sum_{e=1}^{E} \tilde{\beta}^{e} \mathbf{W h} \boldsymbol{h}_{t-2}^{e}+\tilde{\delta} \mathbf{W s p e c}_{t-2}+\tilde{\varphi} \mathbf{W d i v} \boldsymbol{s}_{t-2}+\boldsymbol{\varepsilon}_{t}$

where $\mathbf{W}$ is a (row-standardized) spatial weights matrix.

Equation (5) is a Spatial Durbin Panel Model (SDPM) with spatial and time-period fixed effects (see, for instance, Elhorst, 2014). The spatially lagged variables in the model allow us to control for spatially correlated time-variant unobserved factors, so reducing endogeneity issues (LeSage and Fischer, 2008; Rios et al., 2016).

In order to exclude reverse causation, we carried out a Dumitrescu and Hurlin (2012) test, i.e. a Granger-causality test for panel data in which all the coefficients are allowed to vary across cross-sections in the panel. The test is computed by running standard Granger causality regressions for each cross-section, taking the average of the test statistics $(\bar{W})$ and standardizing it $(\bar{Z})$. The standardized test statistic follows a standard normal distribution.

The test results with one lag (the max order permitted by the limited time span) support the assumption of no reverse causation: the null hypothesis that $\log (\mathrm{GVA} / \mathrm{EMP})$ does not homogeneously Granger-cause the share of foreigners in the population cannot be rejected ( $\bar{W}$ 
$=1.17, \bar{Z}=-.984, p$-value $=.325)$, where instead the null that the share of foreigners in the population does not homogeneously Granger-cause $\log (\mathrm{GVA} / \mathrm{EMP})$ is strongly rejected $(\bar{W}=$ $3.46, \bar{Z}=-5.937, p$-value $=.000)$.

One of the advantages of the Spatial Durbin Model (SDM) is the possibility to express the impact on the dependent variable (GVA per employee) from a change in one of the independent variables as a combination of local and total effects mediated by neighbors' influence, at the same time relaxing the main limitation of the spatial lag model that the ratio between the socalled direct and indirect effects is kept constant across the explanatory variables (see Elhorst, 2010a, 2014).

Following Le Sage and Page (2009), the direct effects of a certain variable must be intended as the effects of a marginal increase of this variable in a certain spatial unit (e.g., the marginal increase of the share of foreigners in province $i$ ) on the dependent variable of the unit itself (e.g., the GVA per employee in the same province $i$ ). In spatial lag and spatial Durbin models, this is actually the result of local effects plus feedback effects mediated by spatial spillovers. On the contrary, the indirect effects are the effects that the change of a variable in a certain unit (increase in the share of foreigners in province $i$ ) produces on the dependent variable of the other units (e.g., GVA per employee in provinces $j$ different from $i$ ).

In particular, taking the matrix of partial derivatives of the expected value of $\boldsymbol{y}_{\mathrm{t}}$ with respect to the explanatory variable $h_{t-1}^{e}$ in all the provinces (from 1 to 103 ), we have:

$$
\left[\frac{\partial \mathrm{E}\left[\boldsymbol{y}_{t}\right]}{\partial h_{1, t-2}^{e}}, \ldots, \frac{\partial \mathrm{E}\left[\boldsymbol{y}_{t}\right]}{\partial h_{103, t-2}^{e}}\right]=(\boldsymbol{I}-\rho \mathbf{W})^{-1}\left(\beta^{e} \mathbf{I}+\tilde{\beta}^{e} \mathbf{W}\right)
$$

LeSage and Pace (2009a, 2009b) define the average direct effect as the average of the diagonal elements of (6), and the average indirect effect as the average of the off-diagonal elements. The sum of the average direct and indirect effects gives the average total effect. ${ }^{11}$

\footnotetext{
${ }^{11}$ The stability conditions of the SDPM are the same as the ones identified for the Spatial Durbin Model (SDM). In particular, as far as the spatial weights matrix $\mathbf{W}$ is concerned, its row and column sums before row-
} 
In the spatial Durbin model (as it happens in the spatial lag model) the key parameter through which global spillovers arise is the spatial autoregressive coefficient $\rho$. It enters in the spatial multiplier $(\boldsymbol{I}-\rho \mathbf{W})^{-1}$ that traces the effect of the linkages between the productivity levels of neighbouring provinces.

The choice of the spatial model to use for the empirical analysis may be based on two different approaches: a specific-to-general approach and a general-to-specific approach (for a general discussion see Elhorst, 2014, Ch. 2 and 3). In the former, the selection between a model without spatial interaction effects, a spatial lag model and a spatial error model is done through (robust) Lagrange Multiplier (LM) tests performed on the residuals of the first (more specific) model. ${ }^{12}$ In the case of panel data models, this must be done after having chosen the best specification without spatial interaction effects (i.e., pooled, one way fixed effect, two way fixed effect, spatial random effect with or without time-period fixed effects). On the contrary, in the generalto-specific approach, the one supported by LeSage and Pace (2009a), one starts from the more general SDPM with spatial and time-period fixed effects and test this model against simpler models by means of Lagrange Ratio (LR) and Wald tests. The SDPM (FE or RE) is estimated using a MLE approach and applying the bias correction procedure spelled out by Lee and $\mathrm{Yu}$ (2010a, b) (see also Elhorst, 2014, Ch. 3).

\section{Results}

In line with the specific-to-general approach, Table 3 reports the results of the (robust) LM tests carried out on the residuals of the specification in Eq. (4), estimated for the GVA per employee

normalization should not diverge to infinity at a rate equal to or faster than the rate of the sample size $\mathrm{N}$ (see Kelejian and Prucha, 1998; 1999; Elhorst, 2014, p. 11). For first-order contiguity matrices, this condition is always satisfied. A sufficient condition for the stationarity of the SDPM in case of symmetric $\mathbf{W}$ is that the spatial autoregressive coefficient $(\rho)$ lies in the interior $\left(1 / \mathrm{w}_{\min }, 1\right)$, where $\mathrm{W}_{\min }$ is the smallest eigenvalue of the rowstandardized version of W (Le Sage and Pace, 2009, pp. 88-89; Elhorst, 2014, p. 11).

${ }^{12}$ The extensions of these tests to spatial panel models have been specified by Anselin et al. (2006) and Elhorst (2010b). 
for the whole economy and the five macro sectors we consider in our analysis (agriculture, industry, construction, high level services and low level services). ${ }^{13}$

Table 3. LM tests on residuals of panel data models with spatial and time-period fixed effects without spatial interaction effects

\begin{tabular}{lrrrrrr}
\hline & Total & Agriculture & Industry & Construction & $\begin{array}{c}\text { High level } \\
\text { services }\end{array}$ & $\begin{array}{c}\text { Low level } \\
\text { services }\end{array}$ \\
\hline LM spatial lag & 51.808 & 31.818 & 2.290 & 125.881 & 1.533 & 11.936 \\
& $(.000)$ & $(.000)$ & $(.130)$ & $(.000)$ & $(.216)$ & $(.001)$ \\
Robust LM spatial lag & 22.290 & 0.1547 & 3.074 & 27.408 & 3.651 & 3.096 \\
& $(.000)$ & $(.694)$ & $(.080)$ & $(.000)$ & $(.056)$ & $(.078)$ \\
LM spatial error & 37.990 & 32.767 & 1.257 & 105.382 & 3.949 & 17.640 \\
& $(.000)$ & $(.000)$ & $(.262)$ & $(.000)$ & $(.047)$ & $(.000)$ \\
Robust LM spatial error & 8.472 & 1.103 & 2.040 & 6.910 & 6.067 & 8.800 \\
& $(.004)$ & $(.294)$ & $(.153)$ & $(.009)$ & $(.014)$ & $(.003)$ \\
\hline \hline
\end{tabular}

Note: $p$-values in parenthesis.

The (robust) LM spatial lag and LM spatial error tests reject the null at the $1 \%$ for the main specification (labour productivity for the whole economy in the LHS). As for the other cases, results are more mixed: the null is mostly rejected at the $10 \%$ level in all the specifications, except for industry and agriculture (for which the null is rejected only by the non-robust versions of LM tests). However, also for these two sectors, we decided to consider a SDPM on the basis of the tests performed in accordance with the general-to-specific approach and carried out on a SDPM model with spatial and time period effects (Table 4). In particular, note that: (i) the Wald and LR spatial lag tests always reject the null of joint non-significance of the spatial lags of independent variables and therefore the SDPM cannot be reduced to a spatial lag panel model $;{ }^{14}$ (ii) the Wald and LR spatial error tests always reject the null, therefore the SDPM is not reducible to a spatial error panel model; (iii) the LR tests for the joint significance of the spatial/time-period fixed effects always reject the null, hence the SDPM with spatial and time-

\footnotetext{
${ }^{13}$ The panel data model with both spatial and time-period fixed effects has been chosen because in all the cases: (i) the HAC-robust $\mathrm{F}$ tests reject at the $1 \%$ level the null of joint non-significance of spatial or time-period fixed effects; (ii) the Hausman tests reject the null of the consistency of the random-effect model with time-period dummies.

${ }^{14}$ The coefficients attached to the spatial lags of the shares of immigrants likely capture the effect of worker commuting (immigrant workers living in a province and working in a neighboring province).
} 
period fixed effects cannot be simplified to a spatial Durbin model without unit and/or time dummies; (iv) the spatial autoregressive coefficient $(\rho)$ is always statistically significant, hence the SDPM cannot be reduced to a Spatial Lag of X (SLX) panel model, i.e. a model with only spatial lags of the independent variables. 
Table 4. Spatial Durbin panel models with spatial and time-period specific effects

\begin{tabular}{|c|c|c|c|c|c|c|c|c|}
\hline & Total & & Agriculture & Industry & Construction & $\begin{array}{l}\text { High level } \\
\text { services }\end{array}$ & $\begin{array}{l}\text { Low lev } \\
\text { service }\end{array}$ & $\begin{array}{l}\text { vel } \\
\text { es }\end{array}$ \\
\hline \multirow[t]{2}{*}{ Albania } & .009 & & $-.150^{* * *}$ & $.066^{* * *}$ & -.030 & $-.048^{* *}$ & .099 & $* * *$ \\
\hline & (1.041) & & $(-2.689)$ & $(2.735)$ & $(-1.182)$ & $(-2.111)$ & $(3.036)$ & \\
\hline \multirow[t]{2}{*}{ Romania } & -.012 & $* * *$ & .017 & -.014 & .006 & .005 & -.044 & $* * *$ \\
\hline & $(-2.974)$ & & $(.640)$ & $(-1.093)$ & $(.474)$ & $(.475)$ & $(-2.735)$ & \\
\hline \multirow[t]{2}{*}{ China } & -.034 & $* * *$ & -.013 & $-.059^{* * *}$ & -.010 & -.005 & -.031 & \\
\hline & $(-5.459)$ & & $(-.320)$ & $(-3.416)$ & $(-.548)$ & $(-.294)$ & $(-1.28)$ & \\
\hline \multirow[t]{2}{*}{ Philippines } & 0.066 & $*$ & -.177 & .101 & -.069 & $.630^{* * * *}$ & 1.254 & $* * *$ \\
\hline & (1.834) & & $(-.761)$ & $(1.125)$ & $(-.644)$ & $(6.61)$ & $(9.203)$ & \\
\hline \multirow[t]{2}{*}{ Morocco } & .0284 & $* *$ & .092 & $-.084^{* *}$ & -.032 & -.010 & .037 & \\
\hline & $(-1.988)$ & & $(.993)$ & $(-2.336)$ & $(-.745)$ & $(-.268)$ & $(.676)$ & \\
\hline \multirow[t]{2}{*}{ Moldova } & -.053 & $* * *$ & -.022 & -.011 & $-.139^{* * *}$ & $-.114^{* * *}$ & -.101 & $* *$ \\
\hline & $(-4.641)$ & & $(-.298)$ & $(-.309)$ & $(-4.063)$ & $(-3.762)$ & $(-2.334)$ & \\
\hline \multirow[t]{2}{*}{ Poland } & .131 & $* * *$ & $1.421^{* * *}$ & -.012 & $-.329^{* * *}$ & -.002 & -.116 & \\
\hline & $(4.733)$ & & $(7.945)$ & $(-.143)$ & $(-3.99)$ & $(-.034)$ & $(-1.107)$ & \\
\hline \multirow[t]{2}{*}{ Tunisia } & .002 & & $-.230^{*}$ & -.024 & -.024 & -.058 & -.001 & \\
\hline & $(0.089)$ & & $(-1.758)$ & $(-.484)$ & $(-.391)$ & $(-1.086)$ & $(-.018)$ & \\
\hline \multirow[t]{2}{*}{ Ukraine } & -.038 & $* *$ & .018 & $-.181^{* * * *}$ & -.031 & -.051 & -.188 & $* * *$ \\
\hline & $(-2.334)$ & & $(.171)$ & $(-3.51)$ & $(-.630)$ & $(-1.178)$ & $(-3.013)$ & \\
\hline \multirow[t]{2}{*}{ India } & -.053 & $* * *$ & -.096 & $-.109^{* * *}$ & $.092^{* *}$ & $-.064 *$ & -.099 & $* *$ \\
\hline & $(-4.241)$ & & $(-1.177)$ & $(-2.937)$ & $(2.456)$ & $(-1.922)$ & $(-2.078)$ & \\
\hline \multirow[t]{2}{*}{ Diversity } & -.042 & $* *$ & $-.328^{* * *}$ & -.059 & $-.116^{* *}$ & $-.288^{* * *}$ & -.099 & \\
\hline & $(-2.574)$ & & $(-3.068)$ & $(-1.456)$ & $(-2.361)$ & $(-6.594)$ & $(-1.576)$ & \\
\hline \multirow[t]{2}{*}{ Specialization } & .0302 & & -.136 & -.044 & .027 & $.178^{* * *}$ & .229 & $* * *$ \\
\hline & (1.479) & & $(-1.025)$ & $(-.843)$ & $(.448)$ & $(3.276)$ & $(2.954)$ & \\
\hline \multirow[t]{2}{*}{$\mathrm{W} \times$ Albania } & .004 & & $.189^{* *}$ & .003 & $.106^{* *}$ & .055 & .041 & \\
\hline & $(.305)$ & & $(2.049)$ & $(.066)$ & $(2.507)$ & $(1.456)$ & $(.755)$ & \\
\hline \multirow[t]{2}{*}{$\mathrm{W} \times$ Romania } & -.028 & $* * *$ & $-.106^{* *}$ & $-.056^{* *}$ & .000 & $-.070^{* * * *}$ & -.053 & $*$ \\
\hline & $(-3.754)$ & & $(-2.255)$ & $(-2.480)$ & $(-.003)$ & $(-3.638)$ & $(-1.916)$ & \\
\hline \multirow[t]{2}{*}{ W $\times$ China } & -.035 & $* * *$ & $.192^{* *}$ & .034 & -.021 & $-.083^{* *}$ & -.110 & $* *$ \\
\hline & $(-2.625)$ & & $(2.208)$ & $(.894)$ & $(-.521)$ & $(-2.321)$ & $(-2.146)$ & \\
\hline \multirow[t]{2}{*}{$\mathrm{W} \times$ Philippines } & .340 & $* * *$ & $1.082^{* *}$ & .058 & .215 & $.497^{* *}$ & -1.657 & $* * * *$ \\
\hline & $(4.585)$ & & $(2.266)$ & $(.329)$ & (.979) & $(2.487)$ & $(-5.909)$ & \\
\hline \multirow[t]{2}{*}{$\mathrm{W} \times$ Morocco } & .111 & $* * *$ & $.227^{* * * *}$ & $.365^{* * *}$ & -.100 & .097 & .082 & \\
\hline & (4.803) & & $(1.512)$ & $(6.715)$ & $(-1.447)$ & (1.578) & $(.934)$ & \\
\hline W $\times$ Moldova & -.017 & & $-.295^{* *}$ & .046 & -.011 & $.156^{* * * *}$ & .091 & \\
\hline & $(-.462)$ & & $(-1.991)$ & $(.654)$ & $(-.166)$ & $(2.579)$ & (1.05) & \\
\hline $\mathrm{W} \times$ Poland & .060 & & $-.868^{* * *}$ & .217 & .125 & .068 & .333 & $* *$ \\
\hline & (1.429) & & $(-3.163)$ & $(1.715)$ & (.997) & $(.614)$ & $(2.099)$ & \\
\hline W×Tunisia & -.205 & $* * *$ & -.293 & $-.494^{* * *}$ & $-.385^{* * *}$ & -.018 & -.204 & \\
\hline & $(-5.70)$ & & $(-1.259)$ & $(-5.527)$ & $(-3.574)$ & $(-.189)$ & $(-1.501)$ & \\
\hline W×Ukraine & .0558 & $* *$ & .037 & .120 & $.189^{* *}$ & .120 & .091 & \\
\hline & (1.959) & & $(.201)$ & (1.374) & $(2.213)$ & (1.582) & $(.837)$ & \\
\hline $\mathrm{W} \times$ India & .0267 & & .124 & .070 & $.204^{* * *}$ & .024 & -.188 & \\
\hline & (1.046) & & $(.751)$ & $(.938)$ & $(2.643)$ & $(.353)$ & $(-1.935)$ & \\
\hline $\mathrm{W} \times$ Diversity & .003 & & $-.34 *$ & $-.222^{* * * *}$ & .083 & .069 & .254 & $* *$ \\
\hline & $(.1096)$ & & $(-1.694)$ & $(-2.949)$ & $(.900)$ & $(.838)$ & $(2.176)$ & \\
\hline $\mathrm{W} \times$ Spec. & .109 & $* * *$ & $-.477^{*}$ & -.096 & -.053 & $.428^{* * *}$ & .565 & $* * *$ \\
\hline & $(2.862)$ & & $(-1.936)$ & $(-.946)$ & $(-.468)$ & $(4.195)$ & $(3.895)$ & \\
\hline$\rho$ & .209 & $* * *$ & $.302^{* * *}$ & $.104^{* *}$ & $.426^{* * *}$ & $-.148^{* * *}$ & .171 & $* * * *$ \\
\hline & $(4.478)$ & & $(6.788)$ & (2.106) & $(1.711)$ & $(-2.772)$ & $(3.553)$ & \\
\hline N. obs. & & 721 & 721 & 721 & 721 & 721 & & 721 \\
\hline FE/RE model & & $\mathrm{FE}$ & $\mathrm{FE}$ & $\mathrm{RE}$ & FE & $\mathrm{FE}$ & & $\mathrm{FE}$ \\
\hline$\sigma^{2}$ & & 003 & .0107 & .0027 & .0023 & .0018 & & 037 \\
\hline $\mathrm{R}^{2}$ & & 950 & .919 & .890 & .913 & .876 & & .953 \\
\hline
\end{tabular}




\begin{tabular}{lrrrrrr} 
corr $^{2}$ & .317 & .182 & .121 & .188 & .274 & .311 \\
Log-L & 2016.79 & 663.74 & 894.05 & 1213.58 & 1313.80 & 1056.24 \\
$\theta$ & - & - & .130 & & - & - \\
& & & $(1.210)$ & & & \\
LR test joint & 3271.30 & 1083.10 & - & 827.66 & 1095.79 & 1801.38 \\
significance & $(.000)$ & $(.000)$ & & $(.000)$ & $(.000)$ & $(.000)$ \\
spatial fixed & & & & & \\
effects & & & & & \\
LR test joint & 168.57 & 14.29 & 61.78 & 51.85 & 97.03 & 86.86 \\
significance & $(.000)$ & $(.027)$ & $(.000)$ & $(.000)$ & $(.000)$ & $(.000)$ \\
time-period & & & & & \\
fixed effects & & & & & \\
& & & & & & \\
Wald test & 95.884 & 57.274 & 88.725 & 41.263 & 77.027 & 77.180 \\
spatial lag & $(.000)$ & $(.000)$ & $(.000)$ & $(.000)$ & $(.000)$ & $(.000)$ \\
LR test spatial & 106.870 & 64.712 & 8.166 & 48.236 & 87.452 & 85.735 \\
lag & $(.000)$ & $(.000)$ & $(.000)$ & $(.000)$ & $(.000)$ & $(.000)$ \\
Wald test & 99.354 & 49.154 & 86.378 & 44.225 & 72.571 & 68.019 \\
spatial error & $(.000)$ & $(.000)$ & $(.000)$ & $(.000)$ & $(.000)$ & $(.000)$ \\
LR test spatial & 11.914 & 59.941 & 97.670 & 52.730 & 84.000 & 78.280 \\
error & $(.000)$ & $(.000)$ & $(.000)$ & $(.000)$ & $(.000)$ & $(.000)$ \\
Hausman test & 53.557 & 66.833 & 15.806 & 6.0376 & 81.857 & 92.055 \\
(FE vs RE) & $(.001)$ & $(.000)$ & $(.920)$ & $(.000)$ & $(.000)$ & $(.000)$ \\
\hline \hline
\end{tabular}

Corr $^{2}$ : squared correlation coefficient between actual and fitted values. $\mathrm{R}^{2}$ computed using the transformed residuals in the random effects SDPM. Fixed-effects SDPM estimated adopting the bias correction procedure suggested by Lee and Yu (2010) (see Elhorst, 2014, Ch.3). Significance at 1\% *, 5\% **, 10\% ${ }^{* * *}$. Asymptotic $t$-statistic ( $p$-value) for coefficient estimates (test results) in parenthesis.

Table 4 reports also the Hausman tests. These tests always strongly reject the null of the random effect (RE) model being consistent for all the specifications but for industry. For this sector, we therefore estimate a RE SDPM with time-period fixed effects. ${ }^{15}$

The spatial autoregressive coefficient $\rho$ is statistically significant and ranges between -.148 (high-level services) and .426 (construction), and it is equal to .209 in the specification for aggregate productivity. Therefore, it satisfies the stationarity condition and confirms the presence of spatial productivity spillovers across provinces.

Table 5 shows the estimates of the direct, indirect and total effects (with associated $t$-values)

\footnotetext{
${ }^{15}$ Since the (robust) LM spatial lag tests had not rejected the null of no spatial lag at the $5 \%$ level and the spatial autoregressive coefficient in the FE SPDM was not statistically significant at the 5\%, we also estimated a Spatial Lag of X (SLX) panel model. Estimates of the direct, indirect and total effects turned out to be rather similar to the ones derived from the RE SDPM in terms of signs, significance and magnitude. Results are available upon request.
} 
based on the coefficient estimates of the SDPMs. ${ }^{16}$

As discussed in Section 3, the direct effect estimates of a covariate measure how the GVA per employee in a province responds on average at a marginal increase of the covariate in the same province. In a spatial Durbin model, this effect is the result of both immediate effects and spatial spillovers. The indirect effects instead measure the average impact of a marginal increase of a covariate in a province in the productivity level of the other provinces. The total effect estimates are the sum of direct and indirect effects and measure the overall average marginal impact on the expected value of labour productivity at the province level. These effects with the associated $t$-statistics for the six cases we consider are reported in Table 5.

As far as aggregate labour productivity is concerned, the direct effects are positive and statistically significant only for immigrant workers from Philippines (.085) and Poland (.136), ${ }^{17}$ while all the other nationalities exert a negative or statistically insignificant direct effect.

The total effects are positive and statistically significant for immigrants from Philippines (.511), Poland (.245) and Morocco (.105). The positive impact of the Filipino community arise from its statistically significant and positive effect in agriculture and high-level services. This last result may not be due to the direct employment of Filipinos in this sector, since they are typically specialised in low-services, as to the fact that they allow to high-skilled workers to concentrate on their work making them free from housework and childcare chores (the estimated direct impact of Filipinos in low-level services is in fact extremely high: 1.186). ${ }^{18}$

\footnotetext{
${ }^{16}$ We checked the robustness of the results using different specifications of the weight matrix: (i) a 5-nearest neighbor matrix; (ii) inverse distance matrix (linear and quadratic versions) with a distance cut-off corresponding to the first quintile. The results turn out to be robust to the alternative specifications of $\mathbf{W}$.

${ }^{17}$ An effect of $0.085(0.136)$ means that the labour productivity is expected to increase about $8.5 \%$ by increasing the local share of immigrants from Philippines (Poland) over total population in the province by one percentage point (p.p.). Note that, although the estimated impacts looks high, since the shares are low, an increase of one p.p. is an extremely large variation in percentage terms of the total immigrants. E.g., for Filipinos (Poles), the mean share across Italian provinces in 2011 is about $0.12 \%(0.18 \%)$, an increase of one p.p. in the share, from $0.12 \%$ $(0.18 \%)$ to $1.12 \%(1.18 \%)$, corresponds to a percentage increase in the total immigrants from Philippines (Poland) amounting to about $843 \%(562 \%)$.

${ }^{18}$ Taking the mean share of the Filipinos in 2011, this means that, if the number of Filipinos in a certain province doubles, labour productivity in low-level services is expected to increase by $14 \%$.
} 
The positive total effect of immigrants from Poland and Morocco on aggregate productivity seems to be driven mainly by their positive impact in agriculture and industry, which offset their negative or insignificant impact in the other sectors.

All the other nationalities do not have a statistically significant effect or have a negative total effect. In particular, people from Romania, China, Moldova and Tunisia seem to exert a negative impact on productivity in the whole economy. Romanians have a negative effect on four out of five sectors (agriculture, industry, high-level and low-level services), while their impact is not statistically significant in the construction sector. Chinese group has a statistically significant negative effect on both high-level and low-level services that offset the total positive impact in agriculture. The negative effect of Moldavians in the whole economy is due to the negative contribution in agriculture and construction, while they do not play any statistically significant effect in the other sectors. Finally, Tunisians have a negative effect in agriculture, industry and construction while they do not seem to produce any effect in high- and low-level services. 
Table 5. Direct, indirect and total effects estimates based on the coefficient estimates of spatial Durbin panel models

\begin{tabular}{|c|c|c|c|c|c|c|c|c|c|}
\hline & \multicolumn{3}{|c|}{ Total } & \multicolumn{3}{|c|}{ Agriculture } & \multicolumn{3}{|c|}{ Industry } \\
\hline & Direct & Indirect & Total & Direct & Indirect & Total & Direct & Indirect & Total \\
\hline \multirow[t]{2}{*}{ Albania } & .009 & .007 & .016 & $-.138^{* * *}$ & .194 & .056 & $.066^{* * * *}$ & .010 & $.075^{* *}$ \\
\hline & (1.113) & $(.435)$ & (1.084) & $(-2.531)$ & (1.628) & $(.476)$ & $(2.723)$ & $(.246)$ & (2.134) \\
\hline Romania & $(-3.424)$ & $(-4.196)$ & $(-6.114)$ & $(.300)$ & $(-2.351)$ & $(-2.169)$ & $(-1.217)$ & $(-2.607)$ & $(-3.568)$ \\
\hline \multirow[t]{2}{*}{ China } & $-.037^{* * * *}$ & $-.052^{* * * *}$ & $-.089^{* * * *}$ & .004 & $.256^{* * *}$ & $.259 *$ & $-.059^{* * * *}$ & .029 & -.029 \\
\hline & $(-5.880)$ & $(-3.151)$ & $(-4.491)$ & $(.085)$ & $(2.113)$ & (1.804) & $(-3.436)$ & (.694) & $(-.582)$ \\
\hline Morocco & $(-1.696)$ & $(4.831)$ & (3.895) & (1.255) & (1.859) & $(2.298)$ & $(-2.187)$ & $(6.804)$ & (5.818) \\
\hline \multirow[t]{2}{*}{ Moldova } & $-.054^{* * * *}$ & -.025 & $-.079^{* * *}$ & -.047 & $-.406^{* *}$ & $-.452 * *$ & -.01 & .049 & .039 \\
\hline & $(-4.499)$ & $(-.899)$ & $(-2.488)$ & $(-.609)$ & $(-2.109)$ & $(-2.034)$ & $(-.289)$ & $(.654)$ & $(.460)$ \\
\hline \multirow[t]{2}{*}{ Poland } & $.136^{* * * *}$ & $.109^{* * *}$ & $.245^{* * * *}$ & $1.391^{* * * *}$ & $-.578^{*}$ & $.813^{* *}$ & -.005 & $.245^{*}$ & $.239^{*}$ \\
\hline & (5.037) & $(2.229)$ & $(4.450)$ & (7.785) & $(-1.654)$ & (2.033) & $(-.064)$ & $(1.788)$ & (1.632) \\
\hline Tunisia & -.009 & $-.246^{* * * *}$ & $-.255^{* * * *}$ & $-.263^{* * *}$ & -.475 & $-.738^{*}$ & -.038 & $-.543^{\text {**** }}$ & $-.582^{\text {**** }}$ \\
\hline India & $(-4.351)$ & $(.565)$ & $(-1.155)$ & $(-1.098)$ & $(.641)$ & $(.234)$ & $(-2.894)$ & $(.797)$ & $(-.555)$ \\
\hline \multirow[t]{2}{*}{ Diversity } & $-.043^{* * *}$ & -.008 & -.052 & $-.37^{* * *}$ & $-.604^{* *}$ & $-.974^{* * *}$ & -.064 & $-.251^{* *}$ & $-.315^{* * *}$ \\
\hline & $(-2.709)$ & $(-.226)$ & $(-1.237)$ & $(-3.445)$ & $(-2.237)$ & $(-3.087)$ & $(-1.568)$ & $(-3.047)$ & $(-3.575)$ \\
\hline \multirow[t]{4}{*}{ Specialization } & $.036^{*}$ & $.140^{* * * *}$ & $.175^{* * *}$ & -.183 & $-.713^{* *}$ & $-.896^{* *}$ & $-.046^{* *}$ & -.108 & -.153 \\
\hline & $(1.708)$ & $(3.042)$ & $(3.111)$ & $(-1.298)$ & $(-1.982)$ & $(-2.04)$ & $(-.845)$ & $(-.983)$ & $(-1.178)$ \\
\hline & \multicolumn{3}{|c|}{ Construction } & \multicolumn{3}{|c|}{ High-level services } & \multicolumn{3}{|c|}{ Low-level services } \\
\hline & Direct & Indirect & Total & Direct & Indirect & Total & Direct & Indirect & Total \\
\hline \multirow[t]{2}{*}{ Albania } & -.019 & $.148^{* *}$ & $.129^{* *}$ & $-.051^{* *}$ & .057 & .006 & $.101^{* * *}$ & .069 & $.170^{* * * *}$ \\
\hline & $(-.770)$ & (2.429) & $(2.026)$ & $(-2.151)$ & (1.568) & $(.214)$ & (3.243) & (1.168) & $(2.978)$ \\
\hline \multirow[t]{2}{*}{ Romania } & .007 & .005 & .012 & .008 & $-.065^{* * *}$ & $-.056^{* * *}$ & $-.046^{* * *}$ & $-.071^{* * *}$ & $-.117^{* * *}$ \\
\hline & $(.533)$ & $(.160)$ & $(.357)$ & $(.723)$ & $(-3.735)$ & $(-4.048)$ & $(-2.964)$ & $(-2.381)$ & $(-4.087)$ \\
\hline
\end{tabular}




\begin{tabular}{|c|c|c|c|c|c|c|c|c|c|}
\hline & $(-.381)$ & (.889) & (.655) & (6.111) & (2.073) & $(5.226)$ & $(8.722)$ & $(-5.033)$ & $(-1.300)$ \\
\hline Morocco & $\begin{array}{r}-.045 \\
(-1.072)\end{array}$ & $\begin{array}{r}-.186 \\
(-1.724)\end{array}$ & $\begin{array}{r}-.232 \\
(-1.951)\end{array}$ & $\begin{array}{r}-.011 \\
(-.284)\end{array}$ & $\begin{array}{r}.086 \\
(1.549)\end{array}$ & $\begin{array}{r}.075 \\
(1.463)\end{array}$ & $\begin{array}{r}.041 \\
(.741)\end{array}$ & $\begin{array}{r}.098 \\
(1.02)\end{array}$ & $\begin{array}{r}.138 \\
(1.383)\end{array}$ \\
\hline Moldova & ${ }^{-.146}{ }^{* * * *}$ & $\begin{array}{r}-.106 \\
(-.906)\end{array}$ & $\begin{array}{r}-.252 \\
(-1.845)\end{array}$ & ${ }^{-.120} 0^{\text {**** }}(-3.918)^{-1}$ & ${ }_{(2.813)}^{.158^{* * *}}$ & $\begin{array}{r}.038 \\
(657)\end{array}$ & $\begin{array}{r}-.097 \\
(-2.364)\end{array}$ & $\begin{array}{r}.086 \\
(.871)\end{array}$ & $\begin{array}{r}-.011 \\
(-.103)\end{array}$ \\
\hline Poland & $\begin{array}{r}(-3.888) \\
-.335 \\
(-4.019)\end{array}$ & $\begin{array}{r}(-.900) \\
-.023 \\
(-.119)\end{array}$ & $\begin{array}{r}(-1.845) \\
-.358 \\
(-1.592)\end{array}$ & $\begin{array}{r}-3.918) \\
-.008 \\
(-.105)\end{array}$ & $\begin{array}{r}(2.813) \\
.059 \\
(.553)\end{array}$ & $\begin{array}{r}.05 /) \\
.051 \\
(.479)\end{array}$ & $\begin{array}{r}(-2.364) \\
-.099 \\
(-.966)\end{array}$ & $\begin{array}{c}.8759 \\
(1.953)\end{array}$ * & $\begin{array}{r}(. .103) \\
.260 \\
(1.289)\end{array}$ \\
\hline Tunisia & $\begin{array}{r}-.072 \\
(-1.164)\end{array}$ & $\begin{array}{r}-.638^{* * * *} \\
(-3.444)^{*}\end{array}$ & ${ }^{-.710^{* * *}}$ & $\begin{array}{r}-.061 \\
(-1.112)\end{array}$ & $\begin{array}{r}-.005 \\
(-.056)\end{array}$ & $\begin{array}{r}-.066 \\
(-.709)\end{array}$ & $\begin{array}{r}-.011 \\
(-.144)\end{array}$ & $\begin{array}{r}-.236 \\
(-1.52)\end{array}$ & $\begin{array}{r}-.247 \\
(-1.343)\end{array}$ \\
\hline Ukraine & $\begin{array}{r}-.007 \\
(-.157)\end{array}$ & ${ }^{.284}$ ** & ${ }^{.277^{* *}}$ & $\begin{array}{r}-.053 \\
(-1.169)\end{array}$ & $\begin{array}{r}.112 \\
(1.531)\end{array}$ & $\begin{array}{r}.058 \\
(1.051)\end{array}$ & ${ }^{-.185^{* * *}}$ & $\begin{array}{r}.069 \\
(.592)\end{array}$ & $\begin{array}{r}-.116 \\
(-1.086)\end{array}$ \\
\hline India & $(3.363)^{* * *}$ & $\begin{array}{r}.392^{* * * *} \\
(3.27)\end{array}$ & ${ }^{.514}{ }^{* * * *}$ & $\begin{array}{c}-.066 \\
(-1.92)\end{array}$ & $\begin{array}{r}.028 \\
(.455)\end{array}$ & $\begin{array}{r}-.038 \\
(-.723)\end{array}$ & ${ }^{-.109}{ }^{* *}$ & $(-2.11)^{-.24}$ & $\begin{array}{r}-.349 \\
(-3.029)\end{array}$ \\
\hline Diversity & ${ }^{-.112}$ *** & $\begin{array}{r}.060 \\
(.392)\end{array}$ & $\begin{array}{r}-.052 \\
(-.292)\end{array}$ & $\begin{array}{r}-.291^{* * * *} \\
(-6.608)\end{array}$ & $\begin{array}{r}.104 \\
(1.42)\end{array}$ & ${ }^{-.188^{* *}}$ & $\begin{array}{r}-.088 \\
(-1.419)\end{array}$ & ${ }^{.286^{* *}}$ & $\begin{array}{r}.198 \\
(1.299)\end{array}$ \\
\hline Specialization & $\begin{array}{r}.028 \\
(.412)\end{array}$ & $\begin{array}{r}-.061 \\
(-.315)\end{array}$ & $\begin{array}{r}-.033 \\
(-.139)\end{array}$ & $(3.057)^{* * * *}$ & $(4.045)^{\text {**** }}$ & ${ }_{(5.127)}^{.531}{ }^{* * *}$ & ${ }^{.254^{* * *}}$ & $\begin{array}{r}.709 \\
(4.086)^{* * *}\end{array}$ & ${ }_{(4.561)^{. * * *}}$ \\
\hline
\end{tabular}

$t$-values in parenthesis. Significance at $1 \%^{*}, 5 \%^{* *}, 10 \%^{* * *}$. Direct, indirect and total effects and related $t$-statistics computed using 1,000 draws from the estimated variance-covariance matrix of parameters (the spatial multiplier $(\mathbf{I}-\rho \mathbf{W})$ is calculated every draw) 
The remaining groups - from Albania, Ukraine, and India - have either a positive or a negative statistically significant effect only in some specific sectors. Albanians exert a total positive effect in industry, construction and low-level services; Ukrainians and Indians positively contributes in the construction sector; finally, Indians have a total negative statistically significant effect in low-level services.

To sum up, our findings show that only three out of the ten foreign groups exert a positive overall effect on labour productivity in the whole economy; instead four out of ten foreign groups have a negative impact in the aggregate, with mixed results for specific sectors. On average, the sector benefiting more from foreign groups is industry; the sector suffering more from the negative contribution of foreign groups is agriculture.

These results are in line with Bettin et al. (2014), who find that, in Italy, an increase in the adoption of foreign workers may change the manufacturing output mix in favour of low skillintensive sectors. This can be due to the fact that Italy mainly attracts unskilled immigrants, and the few high-skilled immigrants moving to this country are often employed in traditional sectors and fill low-skilled jobs, suffering from substantial over-education (Bratti and Conti, 2014).

The negative impact on productivity is also in line with the findings of González and Ortega (2011), Kangasniemi et al. (2012) and Nicodemo (2013) for Spain, and in contrast with the positive effects on productivity growth of Rolfe et al. (2013) for the United Kingdom. In particular, González and Ortega (2011) find for Spain that the response of industry to an increase in unskilled labour force is to use the more abundant type of labour more intensively. Thus, the raise of immigration contributes to change production technologies of industry toward a more labour intensive paradigm, because the availability of cheap labour due to legislative changes in favour of more flexibility labour market introduced by the Prodi Government in 1997-98 caused a decline of the equilibrium capital-labour ratio (Daveri and Parisi, 2010). ${ }^{19}$

\footnotetext{
${ }^{19}$ We also performed a Chow test to detect the presence of a possible structural break in 2008. The Chow test
} 


\section{Conclusions}

In this paper, we applied a spatial econometric framework to assess the impact of immigrant communities of different nationalities on labour productivity in Italy from 2003 to 2011 . The number of foreign residents has increased steadily during this period and their presence has become more and more spatially concentrated (the migration chain) up to 2008, when the advent of the financial crisis changed somehow the pattern.

The empirical analysis is based on a spatial panel model, which allows to assess the role and the strengths of the different communities on labour productivity at the province level, accounting for the existence of spatial productivity spillovers and spatially correlated timevariant unobserved factors.

The most interesting result is the diffused negative impact of foreign groups on productivity, both in the aggregate and at the sector level. Only three out of the ten most important nationalities of immigrant in Italy we consider (i.e., Albania, Romania, China, Philippines, Morocco, Moldova, Poland, Tunisia, Ukraine, and India) turn out to have a direct and total positive effect on productivity (Philippines, Morocco, and Poland). Moreover, we do not find common patterns across sectors and groups of immigrants.

A possible explanation of these findings is that of a spatial mismatch (Kain, 1968) between suitable job opportunities and immigrant skills. According to Gobillon et al. (2007), possible causes of this mismatch are: (i) a high commuting costs-wage ratio, that may deter workers from accepting distant jobs; (ii) low efficiency in the job search process; (iii) labour market discrimination.

A desirable extension of this work would be to estimate their empirical relevance in the Italian

rejects the null for some of the sectors at the 5\% level, so we repeat the analysis dividing the sample into two subperiods: 2005-2007 and 2008-2011. Although the point estimates of the coefficients and of the effects differ in some cases, the main results discussed in the text hold. The results are available at request from the authors. 
labour market. One could ask why foreign people decide to live in locations where the labour market is not able to exploit their skills. A first answer could be given by extending our analysis with a utility maximizing framework where immigrants are assumed as rational individuals who decide to live in those locations because destination-origin differences are such that the expected utility on the destination is still greater than the expected utility at the origin plus the cost of relocating. A second answer come from Haug (2008), who points out that, "as social networks are extended and strengthened by each additional migrant, potential migrants are able to benefit from the social networks and ethnic communities already established in the country of destination" pushing in the background other factors.

Finally, some caveats are worth mentioning. First, our analysis is limited to legal immigrants, although the percentage of undocumented immigrants over the total immigrant population in Italy is among the highest in Europe, ranging from 9.5\% to $15.7 \%$ (Kovacheva and Vogel, 2009). In this respect, Coniglio et al. (2009) have recently pointed out that illegal migrants, especially those with high skills, represent a skill waste for the economic system of the host country, since illegal migrants resort to shadow economy. Other studies (Paniagua, 2009) argue that immigrants (including illegal ones) produce an indirect effect on productivity for the primary role they play in some services, such as the care of elderly and children of Italian families. This favours labour market participation of women. To find ways to control somehow for the effects of illegal immigrants on productivity could represent an interesting venue of research..

Second, the model specification incorporate only the (proxy for) human capital of the ethnic minorities without considering some measure of human capital for the natives. Actually, the measure implicitly assumed in the model for natives' productive specificities is the complement of the percentage of foreign-born population over total population. However, the model could be extended to consider human capital of natives and minorities. Once again, available data on 
human capital is the basic requirement for this extension.

Third, this work attempts to measure the effect of certain minorities to GVA per employee at the province level, but of course migrants actually affect the local (economic and social) system in many other ways. In this regard, Akay et al. (2014) find a positive effect of immigration on natives' well-being in Germany, which is not driven by local labor market conditions.

Our results give room to various policy interventions. The clearest evidence from this study is that the formation of clusters is not in itself a channel to improve productivity. This is probably also linked to the quality of migration and to the under-utilization of skilled labour. This implies that the policies aimed at avoiding spatial concentration and fostering integration and social inclusion could generate positive effects on productivity. The process has to go together with a more receptive labour market in which wages are proportional to skills and professional levels. This would also solve the self-selection problem (Bratti and Conti, 2014), so that immigrants coming to Italy can fully utilise their skills. Up to now, immigrants have been seen mainly as an issue to deal with, but only at times as a missed development opportunity. There seems to be the need to tackle the problem of migration in a different way, a way that would benefit not only the immigrants, but the whole society.

\section{References}

Accetturo A., Manaresi F., Mocetti S. and Olivieri E. (2014), "Don't stand so close to me: The urban impact of immigration", Regional Science and Urban Economics, 45: 45-56.

Akay A., Constant A. and Giulietti C. (2014), "The impact of immigration on the well-being of natives", Journal of Economic Behavior \& Organization 103: 72-92.

Alesina A., Devleeschauwer A., Easterly W., Kurlat S., and Wacziarg R. (2003), "Fractionalization", Journal of Economic Growth, 8: 155-194.

Anselin L. (2003), "Spatial externalities, spatial multipliers, and spatial econometrics", International Regional Science Review, 26: 153-166.

Anselin L., Le Gallo J. and Jayet H. (2006), Spatial panel econometrics, in Matyas L. and 
Sevestre P. (eds), The econometrics of panel data, fundamentals and recent developments in theory and practice, Kluwer, Dordrecht: 901-969.

Barro R.J. (2000), "Inequality and growth in a panel of countries", Journal of Economic Growth, 3: 5-32.

Barro R.J. and McCleary R.M. (2003), "Religion and economic growth across countries", American Sociological Review, 68: 760-781.

Barro R.J. and Sala-i-Martin X. (2003), Economic growth, $2^{\text {nd }}$ edn. MIT Press, Cambridge, MA.

Bettin G., Lo Turco A., and Maggioni D. (2014), "A firm level perspective on migration: the role of extra-EU workers in Italian manufacturing", Journal of Productivity Analysis, 42: $305-325$

Bratti M. and Conti C. (2014), "The effect of (mostly unskilled) immigration on the innovation of Italian regions", IZA DP No. 7922.

Coniglio N., De Arcangelis G. and Serlenga L. (2009), "Intentions to Return of Undocumented Migrants: Illegality as a Cause of Skill Waste", Review of Development Economics, 13(4): 641-657.

Daveri F. and Parisi M.L. (2010), “Temporary Workers and Seasoned Managers as Causes of Low Productivity" Ifo/CESifo \& OECD Conference on Regulation: Political Economy, Measurement and Effects on Performance, Jan. 2010, Munich.

Dumitrescu E.I., and Hurlin C. (2012), "Testing for Granger non-causality in heterogeneous panels", Economic Modelling 29:1450-1460.

Duranton G. and Puga D. (2000), "Diversity and Specialisation in Cities: Why, Where and When Does it Matter?", Urban Studies, 37(3): 533-555.

Easterly W. and Levine R. (1997), “Africa's growth tragedy: Policies and ethnic divisions”, The Quarterly Journal of Economics, 12: 1203-1250.

Elhorst J. P. (2010), “Applied Spatial Econometrics: Raising the Bar”, Spatial Economic Analysis, 5: 9-28.

Elhorst J. P. (2010b), Spatial panel data models, in Fischer M.M. and Getis A. (eds), Handbook of applied spatial analysis, Springer, Berlin: 377-407.

Elhorst J.P. (2014), Spatial Econometrics. From Cross-Sectional Data to Spatial Panels, Springer, Berlin.

Ertur C., Koch W. (2007), "Growth, technological interdependence and spatial externalities: theory and evidence", Journal of Applied Econometrics, 22: 1033-1062.

Etzo I., Massidda C., Piras R. and Mattana P. (2016), "The impact of immigration on output and its components: A sectoral analysis for Italy at regional level", MPRA Paper No. 72300 .

Fingleton B. and Lopez-Bazo E. (2006), "Empirical growth models with spatial effects", 
Papers in Regional Science, 85(2): 177-198.

Fratesi U. and Percoco M. (2014), "Selective migration, regional growth and convergence: Evidence from Italy", Regional Studies, 48: 1650-1668.

de la Fuente, A. and Doménech, R. (2006), "Human capital in growth regressions: how much difference does data quality make? An update and further results", Journal of the European Economic Association, 1(4): 1-36.

González L. and Ortega F (2011), "How do very open economies adjust to large immigration flows? Evidence from Spanish regions", Labour Economics, 18: 57-70.

Gören E. (2014), "How Ethnic Diversity Affects Economic Growth", World Development, 59: 275-297.

Haug S. (2008), "Migration Networks and Migration Decision-Making", Journal of Ethnic and Migration Studies, 34: 585-605.

IDOS (2010), Dossier statistico immigrazione, Caritas/Migrantes Rome.

INEA (2009), Gli immigrati nell'agricoltura italiana, Rome.

Kain J. (1968), "Housing segregation, negro employment, and metropolitan decentralization", Quarterly Journal of Economics, 82: 175-197.

Kangasniemi M., Mas M., Robinson C. and Serrano L. (2012), "The economic impact of migration: Productivity analysis for Spain and the UK", Journal of Productivity Analysis, 38: 333-343.

Kelejian H.H., Prucha I.R. and Yuzefovich Y. (2006), "Estimation problems in models with spatial weighting matrices which have blocks of equal elements", Journal of Regional Science, 46: 507-551.

Kovacheva V. and Vogel D. (2009) "The Size of the Irregular Foreign Resident Population in the European Union in 2002, 2005 and 2008: Aggregated Estimates", Hamburg Institute of International Economics (HWWI), Database on Irregular Migration, Working paper No. 4.

Lee L.F. and Yu J. (2010a), Estimation of spatial autoregressive panel data models with fixed effects, Journal of Econometrics, 154(2):165-185.

Lee L.F. and Yu J. (2010b), Some recent developments in spatial panel data models, Regional Science and Urban Economics, 40:255-271.

Leone Moressa Foundation (2012), Le professioni ricoperte dagli occupati stranieri - anno 2011, Mestre.

LeSage J.P. and Fischer M.M. (2008), "Spatial growth regressions: Model specification, estimation and interpretation", Spatial Economic Analysis, 3: 275-304.

LeSage J. P. and Pace R. K. (2009a), Introduction to spatial econometrics, Taylor \& Francis 
CRC Press, Boca Raton.

LeSage J. P. and Pace R. K. (2009b), "Spatial econometrics models", in: Fischer M.M. and Getis A (eds.) Handbook of applied spatial analysis. Springer, Berlin: 355-576.

Li, Q. (2014), "Ethnic diversity and neighborhood house prices", Regional Science and Urban Economics, 48: 21-38.

Llull, J. (2008) “The Impact of Immigration on Productivity.” CEMFI Working Paper 0802, Center for Monetary and Financial Studies, Madrid.

Mankiw N.G. (1995), “The Growth of Nations", The Brooking Papers on Economic Activity, 1: 275-326.

Ministero dell'Interno (2007), $1^{\circ}$ Rapporto sugli immigrati in Italia, Rome.

Ministero dell'Interno (2012), $2^{\circ}$ Secondo rapporto annuale sul mercato del lavoro degli immigrati - 2012, Rome

Montalvo J. and Reynal-Querol M. (2005), "Ethnic diversity and economic development", Journal of Development Economics, 76: 293-323.

Mussa, A., Nwaogu, U. G. and Pozo, S. (2017), "Immigration and housing: A spatial econometric analysis", Journal of Housing Economics, 35: 13-25.

Nicodemo C. (2013), "Immigration and labor productivity: New empirical evidence for Spain”, IZA DP No. 7297.

Noland M. (2005), "Religion and economic performance”, World Development, 8: 1215-1232.

OECD (2016), International Migration Outlook 2016, OECD Publishing, Paris.

Ozgen C., Nijkamp P. and Poot J. (2013), "The impact of cultural diversity on firm innovation: evidence from Dutch micro-data", IZA Journal of Migration 2(18): 1-24.

Paniagua T.A. (2009), "Burden or Resource? The Positive Impact of Immigration on the Italian Welfare State", Ph.D. Dissertation, University of North Carolina.

Peri G. (2012), “The effect of immigration on productivity: Evidence from U.S. States", The Review of Economics and Statistics 94(1): 348-358.

Quah D. (1996), "Regional Convergence Clusters across Europe”, European Economic Review, 40: 1951-1958.

Ramos P., Suriñach J. and Artís M. (2010), "Human capital spillovers, productivity and regional convergence in Spain”, Papers in Regional Science, 89: 435-448.

Rey S. and Montouri B. (1999), "US Regional Income Convergence: A Spatial Econometric Perspective”, Regional Studies 33: 143-156.

Rios V., Pascual A.P. and Iraizoz Apezteguia B. (2016), "Development Differentials and Interaction Effects in the European Regions: A Study Based on the Regional Lisbon 
Index”, Tijdschrift voor Economische en Sociale Geografie, 107: 347-364.

Rolfe H., Rienzo C., Lalani M. and Portes J. (2013), "Migration and productivity: employers' practices, public attitudes and statistical evidence", National Institute of Economic and Social Research, London.

Sala-i-Martin X., Doppelhofer G. and Miller, R.I. (2004), "Determinants of long-run growth: A Bayesian averaging of classical estimates (BACE) approach", American Economic Review, 94: 813-835.

\section{Appendix}

Table A1. Moran's I by ethnic group and year

\begin{tabular}{cccccccccccc}
\hline Year & Total & Albania & Romania & Cina & Philippines & Morocco & Moldova & Poland & Tunisia & Ukraine & India \\
2003 & $.6138^{* * *}$ & $.5663^{* * *}$ & $.4818^{* * *}$ & -.0269 & $.0807^{*}$ & $.5970^{* * *}$ & $.1388^{* * *}$ & $.4120^{* * *}$ & $.1270^{*}$ & $.5563^{* * *}$ & $.2874^{* * *}$ \\
2004 & $.6441^{* * *}$ & $.5770^{* * *}$ & $.4987^{* * *}$ & -.0282 & $.1071^{* *}$ & $.6026^{* * *}$ & $.2252^{* * *}$ & $.4578^{* * *}$ & $.1052^{* *}$ & $.4700^{* * *}$ & $.2825^{* * *}$ \\
2005 & $.6664^{* * *}$ & $.5971^{* * *}$ & $.5274^{* * *}$ & -.0166 & $.1041^{* *}$ & $.6218^{* * *}$ & $.1794^{* * *}$ & $.4663^{* * *}$ & $.1043^{* *}$ & $.4547^{* * *}$ & $.2882^{* * *}$ \\
2006 & $.6865^{* * *}$ & $.6027^{* * *}$ & $.5425^{* * *}$ & -.0175 & $.1114^{* *}$ & $.6353^{* * *}$ & $.1771^{* * *}$ & $.4645^{* * *}$ & $.1033^{* *}$ & $.4558^{* * *}$ & $.3052^{* * *}$ \\
2007 & $.6978^{* * *}$ & $.6116^{* * *}$ & $.5455^{* * *}$ & -.0200 & $.0951^{* *}$ & $.6537^{* * *}$ & $.1729^{* * *}$ & $.4644^{* * *}$ & $.1078^{* *}$ & $.4636^{* * *}$ & $.3044^{* * *}$ \\
2008 & $.7141^{* * *}$ & $.6140^{* * *}$ & $.5198^{* * *}$ & -.0208 & $.1085^{* *}$ & $.6603^{* * *}$ & $.2151^{* * *}$ & $.4379^{* * *}$ & $.1202^{* *}$ & $.4572^{* * *}$ & $.3165^{* * *}$ \\
2009 & $.7191^{* * *}$ & $.6139^{* * *}$ & $.5119^{* * *}$ & -.0181 & $.1203^{* *}$ & $.6704^{* * *}$ & $.2397^{* * *}$ & $.4447^{* * *}$ & $.1297^{* *}$ & $.4557^{* * *}$ & $.3186^{* * *}$ \\
2010 & $.7120^{* * *}$ & $.6173^{* * *}$ & $.5067^{* * *}$ & -.0201 & $.1170^{* *}$ & $.6735^{* * *}$ & $.2354^{* * *}$ & $.4302^{* * *}$ & $.1273^{* *}$ & $.4443^{* * *}$ & $.3046^{* * *}$ \\
2011 & $.6970^{* * *}$ & $.6132^{* * *}$ & $.4957^{* * *}$ & -.0266 & $.1259^{* *}$ & $.6722^{* * *}$ & $.2444^{* * *}$ & $.4334^{* * *}$ & $.1163^{* *}$ & $.4394^{* * *}$ & $.2816^{* * *}$ \\
\hline
\end{tabular}

Significance at ${ }^{*} 10 \%,{ }^{* *} 5 \% ;{ }^{* * *} 1 \%$ confidence level, based on bootstrapped $p$-values. 